Jpn. J. Human Genet. 27, 121-130, 1982

\title{
GENETIC POLYMORPHISMS IN ISOLATED COMMUNITIES
}

\author{
Norio FujIKI, Itsuro Nishigakr,* and Kazuo MANo \\ Department of Internal Medicine and Medical Genetics, \\ Fukui Medical School, Fukui 910-11, Japan \\ *Department of Genetics, Institute for Developmental \\ Research, Kasugai 480-03, Japan
}

The Japanese Subcommittee for the International Biological Program (Matsunaga, 1975) has compiled more than 40 kinds of polymorphic traits. The current issue for "The Distribution of the Human Blood Groups and Other Polymorphisms" (Mourant et al., 1976) contains data on over 60 kinds of polymorphic traits, based upon newly developed immunochemical and electrophoretic techniques. The study of genetic polymorphisms has greatly contributed to our knowledge not only of the genetic characteristics of a given individual and population but of our understandings of evolutionary changes of protein molecules and population structure. In addition, the disease susceptibility occurring in conjunction with a given polymorphic trait has been studied.

\section{DATA OBTAINED}

\section{Gene frequency of various genetic polymorphic traits in isolated communities}

We have surveyed genetic polymorphisms in several isolated communities in Japan (Fig. 1 and Table 1) (Fujiki et al., 1968; Yamamoto et al., 1972). We examined blood types; ABO, MN, Rh, red cell enzyme types; AK, Dia, GOT, GPT, $\mathrm{AcP}, \mathrm{EsD}, 6 \mathrm{PGD}, \mathrm{PGM}$, and serum protein types; $\mathrm{Hp}, \mathrm{Tf}, \mathrm{Gc}$, and estimated their gene frequencies (Tables 2 and 3) (Fujiki and Nishigaki, 1980).

Each isolated community revealed different values of gene frequencies, compared with neighboring communities, owning to such factors as geographic distribution, adaptability to environmental agents, consanguinity, isolation and small sample size. In an infinitely large population, gene frequencies may be only slightly affected by mutation and selections, while in an isolated population remarkable alterations due to genetic drift and founder's effect may be observed. Disasters such as epidemic, famine and flood, abruptly change gene frequencies by chance. One of the authors (Nishigaki, 1978) estimated the mean heterozygosity value and standard deviation for gene frequencies of ten polymorphic traits. He obtained mean heterozygosity value as high as $19.4 \%$ in To village, which was higher than that of $17.7 \%$ for all of Japan estimated by Ishimoto and $18.1 \%$ for England estimated by Harris. At present our unexpectedly high value is inexplicable. 


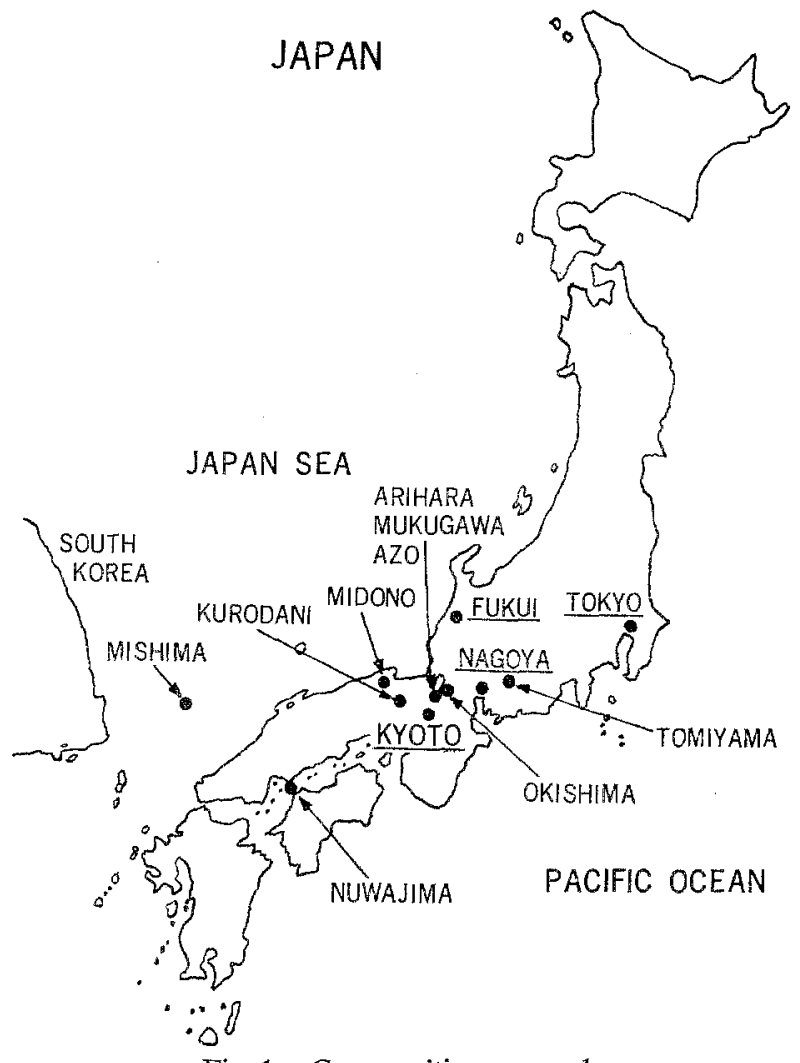

Fig. 1. Communities surveyed.

Table 1. Consanguinity rates and'mean inbreeding coefficients in isolates.

\begin{tabular}{|c|c|c|c|c|c|c|c|c|c|c|c|}
\hline & & & & Inbred & Inbred & & & & & $\begin{array}{c}\text { Mean in } \\
\text { coeff }\end{array}$ & $\begin{array}{l}\text { oreeding } \\
\text { cient }\end{array}$ \\
\hline & RMca & & conpo & & & & & & & & it \\
\hline M & $\mathrm{H}$ & 1,975 & 517 & 92 & 17.8 & 52 & 13 & 15 & 14 & 0.00771 & 0.00506 \\
\hline Is. & $\mathrm{U}$ & 737 & 192 & 46 & 24.0 & 23 & 9 & 4 & 12 & 0.01165 & 0.01164 \\
\hline $\mathrm{N}$ & $\mathrm{M}$ & 1,191 & 340 & 52 & 15.3 & 23 & 8 & 11 & 6 & 0.00620 & 0.00536 \\
\hline Is. & $K$ & 648 & 175 & 15 & 8.6 & 7 & 2 & 2 & 4 & 0.00304 & 0.00480 \\
\hline O & Is. & 686 & 286 & 82 & 28.7 & 40 & 11 & 19 & 12 & 0.01135 & 0.01065 \\
\hline $\mathrm{Mi}$ & Vill. & 161 & 54 & 14 & 25.9 & 7 & 0 & 2 & 6 & 0.01125 & 0.01770 \\
\hline $\mathrm{K}$ & $\mathrm{Ku}$ & 243 & 85 & 8 & 9.4 & 5 & 3 & 0 & 0 & 0.00489 & 0.00728 \\
\hline Vill. & Ok & 136 & 48 & 16 & 33.3 & 6 & 6 & 2 & 2 & 0.01628 & 0.01462 \\
\hline $\mathrm{Ar}$ & Vill. & 181 & 69 & 40 & 58.0 & 13 & 9 & 11 & 7 & 0.01881 & 0.02427 \\
\hline $\mathrm{Mu}$ & Vill. & 235 & 83 & 29 & 34.9 & 6 & 3 & 10 & 11 & 0.00901 & 0.00519 \\
\hline $\mathrm{Az}$ & Vill. & 251 & 95 & 20 & 21.1 & 13 & 3 & 1 & 5 & 0.01053 & 0.00915 \\
\hline To & Vill. & 245 & 156 & 48 & 30.8 & 20 & 12 & 11 & 5 & 0.00807 & 0.00736 \\
\hline
\end{tabular}


Table 2. Gene frequencies of polymorphic traits in isolates (I) -Blood groups and serum protein types-

\begin{tabular}{|c|c|c|c|c|c|c|c|c|c|c|c|c|c|c|}
\hline \multirow{3}{*}{\multicolumn{2}{|c|}{ Area }} & \multicolumn{13}{|c|}{ Traits } \\
\hline & & \multicolumn{3}{|c|}{$\mathrm{ABO}$} & \multicolumn{2}{|c|}{$\mathrm{MN}$} & \multicolumn{2}{|c|}{ Rh } & \multicolumn{2}{|c|}{$\mathrm{Hp}$} & \multicolumn{2}{|c|}{$\mathrm{Tf}$} & \multicolumn{2}{|c|}{$\mathrm{Gc}$} \\
\hline & & $I^{\mathrm{A}}$ & $I^{\mathrm{B}}$ & $I^{\circ}$ & $G^{\mathrm{MI}}$ & $G^{\mathrm{N}}$ & $D$ & $d$ & $H p^{1}$ & $H p^{2}$ & $T f^{\mathrm{C}}$ & $T f^{\mathcal{D}}$ & $G c^{1}$ & $G c^{2}$ \\
\hline $\mathbf{M}$ & Is. & 0.246 & 0.178 & 0.553 & 0.533 & 0.467 & - & - & - & - & - & - & - & - \\
\hline $\mathrm{N}$ & Is. & 0.220 & 0.205 & 0.597 & 0.547 & 0.453 & - & - & - & 一 & - & - & - & - \\
\hline $\mathrm{O}$ & Is. & 0.333 & 0.170 & 0.479 & 0.672 & 0.328 & $(407)$ & (3) & 0.383 & 0.617 & $(250)$ & (1) & 0.619 & 0.381 \\
\hline $\mathrm{Mi}$ & Vill. & 0.285 & 0.457 & 0.258 & - & - & - & - & - & - & - & - & - & - \\
\hline $\mathrm{K}$ & Vill. & 0.243 & 0.187 & 0.675 & 0.613 & 0.387 & $(73)$ & $(0)$ & 0.205 & 0.795 & $(142)$ & $(0)$ & - & - \\
\hline $\mathrm{Ar}$ & Vill. & 0.317 & 0.198 & 0.485 & 0.278 & 0.722 & $(90)$ & $(0)$ & 0.117 & 0.852 & ( 89$)$ & (1) & - & - \\
\hline Mu & Vill. & 0.365 & 0.137 & 0.498 & 0.517 & 0.483 & (149) & $(0)$ & $0.212^{\mathrm{a}}$ & $0.788^{a}$ & $(121)$ & (0) & - & - \\
\hline $\mathrm{Az}$ & Vill. & 0.337 & 0.154 & 0.509 & 0.524 & 0.476 & $(143)$ & $(0)$ & 0.298 & 0.702 & $(115)$ & $(0)$ & - & - \\
\hline To & Vill. & 0.224 & 0.227 & 0.549 & 0.586 & 0.414 & $(185)$ & $(0)$ & 0.170 & 0.830 & 0.907 & 0.093 & - & - \\
\hline \multicolumn{2}{|c|}{ Kinki area } & 0.278 & 0.182 & 0.540 & 0.558 & 0.442 & 0.965 & 0.035 & 0.279 & 0.721 & 0.988 & 0.012 & 0.737 & 0.263 \\
\hline
\end{tabular}

Table 3. Gene frequencies of polymorphic traits in isolates (II) -...Red cell enzyme types_-_

\begin{tabular}{|c|c|c|c|c|c|c|c|c|}
\hline \multicolumn{2}{|c|}{$\mathrm{AcP}$} & \multicolumn{3}{|c|}{$P G M_{1}$} & \multicolumn{2}{|c|}{ G6PD } & \multicolumn{2}{|c|}{ 6PGD } \\
\hline$p^{a}$ & $p^{\mathrm{b}}$ & $P G M_{1}^{1}$ & $P G M_{1}^{2}$ & $P G M_{1}^{7}$ & $B^{+}$ & $B^{-}$ & $P G D^{A}$ & $P G D \mathrm{C}$ \\
\hline- & - & - & - & - & - & - & - & - \\
\hline - & - & - & - & - & - & - & - & - \\
\hline 0.181 & 0.819 & - & - & - & (112) & $(0)$ & (112) & $(0)$ \\
\hline- & - & - & - & - & - & - & - & - \\
\hline 0.079 & 0.921 & 0.851 & 0.149 & 0.000 & $(73)$ & $(0)$ & $(72)$ & (1) \\
\hline 0.219 & $0.781^{\mathrm{a}}$ & 0.856 & 0.144 & 0.000 & $(90)$ & $(0)$ & $(990)$ & (0) \\
\hline 0.156 & 0.844 & 0.829 & 0.171 & 0.000 & (149) & (0) & (149) & $(0)$ \\
\hline 0.231 & 0.829 & 0.930 & 0.070 & 0.000 & (143) & $(0)$ & (143) & $(0)$ \\
\hline 0.235 & 0.765 & 0.704 & 0.261 & $0.035^{a}$ & (112) & (0) & (112) & $(0)$ \\
\hline 0.210 & 0.790 & 0.772 & 0.217 & 0.011 & 1.000 & & 0.915 & 0.085 \\
\hline
\end{tabular}

\begin{tabular}{|c|c|c|c|c|c|}
\hline \multicolumn{2}{|c|}{$\mathrm{ADA}$} & \multicolumn{2}{|c|}{$\mathrm{ESD}_{S}$} & \multicolumn{2}{|c|}{ GPT } \\
\hline$A D A_{\mathfrak{r}}$ & $A D A^{2}$ & $E s D^{1}$ & $E s D^{2}$ & $G p t^{1}$ & $G p t^{2}$ \\
\hline - & - & - & - & - & - \\
\hline - & - & - & - & - & $\ldots$ \\
\hline 0.993 & 0.007 & - & - & - & - \\
\hline - & - & 一 & - & - & - \\
\hline 一 & - & - & - & - & - \\
\hline- & - & - & - & - & - \\
\hline- & - & - & - & - & - \\
\hline - & - & - & - & - & - \\
\hline 0.986 & 0.014 & 0.638 & 0.362 & $0.667^{\mathrm{a}}$ & $0.333^{\mathrm{a}}$ \\
\hline 0.972 & 0.028 & 0.649 & 0. 351 & 0.623 & 0.377 \\
\hline
\end{tabular}

To Vill.: AK 1 (185), GOT 1 (184) 2-1 (1), Dia 1 (185). ( ), observed no. a variant. 


\section{Variant forms of polymorphic traits}

Our study of consanguinity in isolated communities can not only clarify the genetic constitutions of a given individual and population, but also demonstrate rare variants such as $P G M_{1}$ 7-7 homozygotes or $G p t^{0}$ heterozygotes, according to electrophoretic and enzyme assay on the basis of family survey.

The distribution of PGM phenotypes of 171 individuals was determined in To village, where the frequencies of the $P G M_{1}{ }^{7}$ allele was 0.0380 , while among neighboring populations it was 0.0114 . Moreover, one rare $P G M_{1}{ }^{7}$ homozygote (PGM 7-7) and one heterozygote (7-2) were detected. The existence of the homozygote $P G M_{1}{ }^{7}$ is most likely attributable to the specific genetic structure of this community with high consanguinity (Table 4) (Nishigaki et al., 1978).

The quantitative difference between three common phenotypes of the red cell enzyme GPT was demonstrated in To village (Table 5). The mean activity of this enzyme was $6.47 \mu / \mathrm{g} \mathrm{Hb}$ for GPT 1, 4.52 for GPT 2-1, and 2.65 for GPT 2 (theoretically $3: 2: 1$ ), which is compatible with the finding that the red cell $G p t^{1}$ gene product has a catalytic activity about 2.5 times higher than that of $G p t^{2}$.

In addition, we found one pedigree which did not show the typical segregation pattern of this codominant gene Gpt in To village. There was a discrepancy between the parents, II-7 and II-8 and their son III-5. Other examined genetic markers did not show such discrepancies from the Mendelian pattern, so that parental exclusion was not considered responsible for this single anomaly. An alternative explanation is the presence of a silent gene allele which would not participate in the determina-

Table 4. Distribution of phenotypes and allele frequencies for $\mathrm{PGM}_{1}$ in the community surveyed.

\begin{tabular}{lccccccc}
\hline & \multicolumn{7}{c}{ PGM $_{1}$ phenotype } \\
\cline { 2 - 7 } & 1 & $2-1$ & 2 & $7-1$ & $7-2$ & 7 & Total \\
\hline Observed & 83 & 65 & 11 & 10 & 1 & 1 & 171 \\
Percentage & 48.5 & 38.0 & 6.4 & 5.9 & 0.6 & 0.6 & 100.0 \\
Expected & 84.9 & 62.0 & 11.3 & 9.2 & 3.3 & 0.2 & 170.9 \\
\hline Allele frequency & $P G M_{1}^{1}=0.7047$ & $P G M_{1}{ }^{2}=0.2573$ & $P G M_{1}{ }^{7}=0.0380$
\end{tabular}

$\chi^{2}=5.0682 ; 3$ d.f.; $0.25>p>0.10$.

Table 5. Mean levels of red cell GPT activity classified according to phenotypes.

\begin{tabular}{lcccccc}
\hline & \multicolumn{7}{c}{ GPT phenotypes } \\
\cline { 2 - 7 } & Total & 1 & $2-1$ & 2 & $1-0$ & $2-0$ \\
\hline Number & 376 & 138 & 167 & 69 & 1 & 1 \\
Percent & 100.0 & 36.7 & 44.4 & 18.3 & 0.3 & 0.3 \\
GPT activity (units/g Hb) & & 6.47 & 4.52 & 2.65 & 2.22 & 0.98 \\
\hline
\end{tabular}




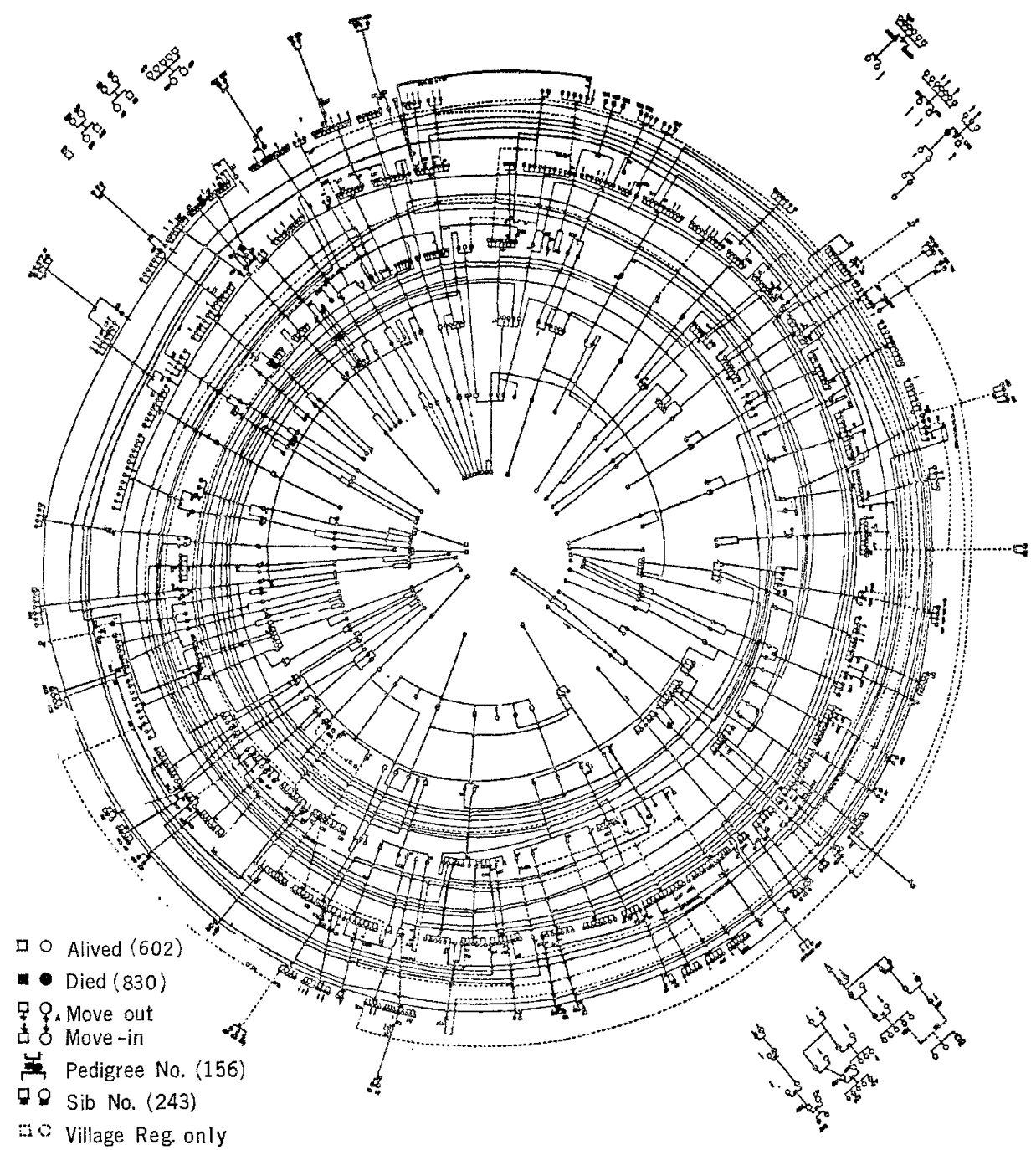

Fig. 2. Pedigree chart of To village.

tion of GPT phenotype. This fact would suggest the probable existence of a silent allele, $G p t^{0}$. Therefore, II-7, II-8 and III-5 have genotypes of $G p t^{2} / G p t^{2}, G p t^{1} / G p t^{0}$ and $G p t^{2} / G p t^{0}$ respectively, which appeared in the GPT 2, GPT 1 and GPT 2 in phenotypic electrophoretic patterns. Heterozygotes with $G p t^{0}$ exhibit less than half normal activity (Fig. 3). At present these heterozygotes are all healthy. In summary, with these quantitative data and electrophoretic patterns from family studies, the existence of two heterozygotes with the silent allele $G p t^{0}$ was confirmed (Nishigaki et al., 1980).

In haptoglobin survey, three families (two in $\mathrm{Mu}$ and one in Ar) with atypical 


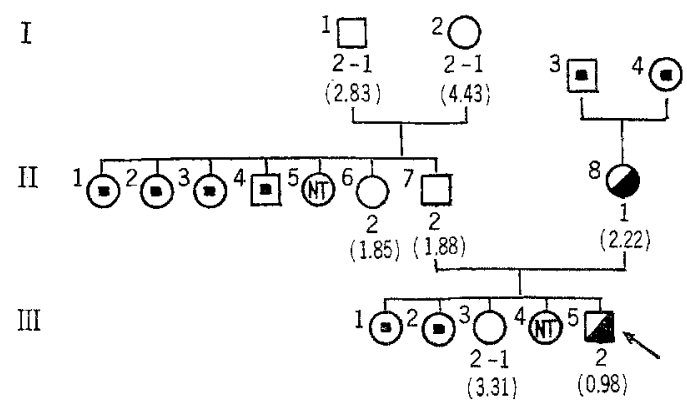

Fig. 3. Pedigree chart of family indicating atypical segregation of GPT phenotypes. (GPT phenotypes and (enzyme activities) are given below each symbol. Half black or square black shows individuals possibly heterozygous for $G P T_{0}$ and residents moved-out, respectively. Proband indicated by arrow. NT, not tested.)

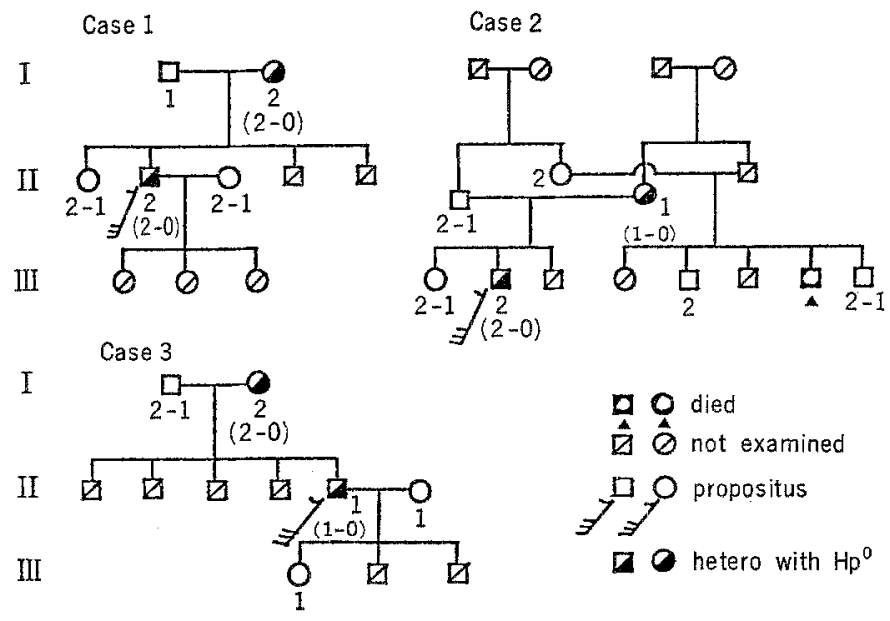

Fig. 4. Atypical segregation of Hp types (Kanazawa, 1971).

segregation of $\mathrm{Hp}$ phenotype were encountered. There was strong evidence of the presence of the $H p^{0}$ gene to account for the $\mathrm{Hp} \mathrm{1-1} \mathrm{electrophoretic} \mathrm{pattern} \mathrm{in}$ presumed heterozygotes genotypically $H p^{0} / H p^{1}$, and for $\mathrm{Hp} \mathrm{2-2} \mathrm{genotypically} H p^{0} \%$ $H p^{2}$ (Fig. 4). Such a silent $H p^{0}$ allele results in an amount of $H p$ too low for immunodiffusion determination. These results obtained from this study so far also coincide well with the hypothesis of a silent $H p^{0}$ allele (Kanazawa, 1971).

3. Relations between diseases and genetic susceptibility

In order to clarify the morbidity of some polygenic diseases, various genetic polymorphic traits relating to diseases are examined. For example, genetic determinants in neoplasia may be reflected in a relationship to certain blood types. For the $\mathrm{ABO}$ blood types, blood type $\mathrm{A}$ is associated with gastric cancer, but no other 
Table 6. Relative risk (Woolf's value) of polymorphic traits among blood dyscrasia.

\begin{tabular}{lccc}
\hline & Phenotype & Apl. & Leuk. \\
\hline ABO & O & 1.2630 & $0.6879^{*}$ \\
\hline AcP & B & 1.5938 & $0.3337^{*}$ \\
ADA & 1 & 0.7225 & $0.2463^{*}$ \\
EsD & 1 & 0.5686 & 0.9347 \\
GPG & $\mathrm{A}$ & 0.8233 & 0.8035 \\
GPT & 1 & 1.5548 & 1.4148 \\
PGM & 1 & $0.5591^{*}$ & 0.6350 \\
GOT & 1 & $0.1910^{*}$ & 0.4266 \\
Hp & 1 & 1.8137 & 1.2994 \\
Tf & $\mathrm{C}$ & 0.3617 & 0.8517 \\
\hline
\end{tabular}

$* \mathrm{p}<0.05$.

consistent correlation has been found. However, wide use of red cell enzyme types and serum protein types may possibly provide new opportunities to detect different associations. Our recent preliminary study suggests relative risk of some polymorphic traits among blood dyscrasia (Table 6) (Fujiki et al.). A slight association between $\mathrm{Hp} \mathrm{1-1}$ and lower values of hemoglobin concentration was found in Ar village, where there was also a much higher prevalence of anemia. However, we could not find a close relationship in Ok village, where there was less anemia (Wada, 1978).

\section{Application of polymorphic data}

We reported previously the study of polymorphisms as applied to population genetics. As an example, we estimated, in Ar village, the inbreeding coefficient, effective population size, and genetic distance. Here we briefly introduce the results.

i) Estimation of inbreeding coefficients. Although reports have been published now to estimate inbreeding coefficients using Koseki records as an information source, this pedigree study method is hardly possible to ascertain remote consanguinity (Fujiki, 1981). Kinship bioassay method and correlation method are regarded as alternatives to pedigree study. Through the former method the inbreeding coefficient can be estimated as the degree of deviation from the Hardy-Weinberg equilibrium. Through the latter method the coefficient of kinship can be estimated by distance or isonomy. The latter method was originally invented to apply to a large-sized population, but we deem it permissible to apply this method even to small populations, unless they are inconsistent with Hardy-Weinberg equilibrium. The mean inbreeding coefficient in Ar village was estimated to be 0.0243 by pedigree 
study, 0.0514 by phenotype bioassay and 0.0590 by correlation method. The low estimate from pedigree study may be attributed either to an incomplete ascertainment of inbreeding in the ancestors, while the high estimate by the bioassay and correlation methods may be attributed to sampling errors and unknown technical difficulties. The true estimate probably lies between the extreme values (Yamamoto et al., 1974a).

ii) Effective population size. Effective population size is one of the important characteristics in a given population. We have applied both Yasuda's formula assaying random genetic drift and Morton's model from the evolution of the kinship coefficients to our study of small isolated communities. The gene frequencies of 11 loci of $\mathrm{ABO}, \mathrm{MN}, \mathrm{Hp}, \mathrm{AcP}$, and PGM were transformed in each generation (II-IV) to values expressed as the Arcsine. The variance effective size was 6 in generation III and 18 in generation IV, and the ratio effective to observed size are 0.18 and 0.90 respectively. This result suggests that the magnitude of random genetic drift is different in each generation. This might be due to misclassification of individuals by generations, different migration rate, or too small population size examined (Yamamoto et al., 1974b).

iii) Transitory changes of gene frequency of blood types. The data of blood frequency types in $\mathrm{OK}$ island were investigated 35 years ago. There was a large deviation of the gene frequency of $\mathrm{ABO}$ and $\mathrm{MN}$ blood types from neighboring populations due to the highly inbred structure on Ok island. Compared with our present data, there is a remarkable difference between present and past frequencies. It is thought that genetic drift, simple sampling error or some selective pressure presumably accounts for the differences.

iv) Genetic distance. As an overview of the genetic relationship between the surveyed communities, Cavalli-Sforza and Edwards' genetic distance test was performed for the gene frequency of 11 polymorphic traits. The phenotypic distribution in our isolated communities deviated somewhat, judging from $\chi^{2}$ test for heterogenuity among them. We also formulated genetic distance in the form of a dendrogram, which was calculated through Morton's program, using the phenotypic distribution of 5 polymorphic traits, $\mathrm{ABO}, \mathrm{MN}$, AcP, PGM and $\mathrm{Hp}$ (Fig. 5). Population size may be too small in each community to regard this dendrogram as completely authentic, but the result was consistent with the geographic distance among the communities, reflecting the migration pattern.

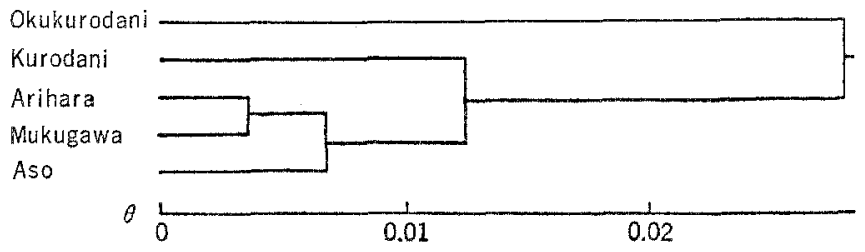

Fig. 5. Dendrogram of isolates surveyed (Yamamoto, 1972). 


\section{SUMMARY}

Isolated communities offer a unique opportunity for the study of biological and social consequences of consanguinity and migration. The studies of genetic polymorphisms have contributed greatly, not only to knowledge of the genetic constitution of a given individual and population, but also to clarify either relationship between structure and function of polymorphic traits or the susceptibility to multifactorial diseases, in which interaction between the gene and environment cannot be ignored.

For over 20 years, we have investigated the effect of consanguinity and genetic polymorphisms in 9 isolated communities in western Japan. We reported here different values of gene frequency for each polymorphic trait, compared with the neighboring communities and described how we applied these data to clarification of the genetic constitution of isolated communities as well as of genetic susceptibility to some diseases.

Acknowledgement This paper was presented at the Symposium on Genetic Markers in Blood at the 26th Annual Meeting of the Japan Society of Human Genetics at Fukuoka on November 7, 1981, based on data previously obtaixed as a part of research projects of the Japanese Committee of the International Biological Program and continuously supported by grants from the Ministry of Education, Science and Culture of Japan, by U.S. Public Health Services Grants, by WHO Research Training Grants and by a Dawa Health Foundation Grant.

\section{REFERENCES}

1) Fujiki, N., Yamamoto, M., Takenaka, S., Ishimaru, T., Takanashi, T., Sugimoto, N., Nakajima, K., and Masuda, M. 1968. A study of inbreeding in some isolated populations. Jpn. J. Human Genet. 12: 105-125.

2) Fujiki, N., and Nishigaki, I. 1980. Consanguinity and polymorphisms in the isolated communities. Jpn. J. Const. Med. 44: 62-66.

3) Fujiki, N., Nishigaki, I., Itoh, T., Tsukahara, R., and Mano, K. 1981. Clinicogenetic study on dyshematopoiesis. (VII) Polymorphisms in blood dyscrasia. Ann. Rep. Study Group on Dyshematop. for 1980 (in Japanese). 68-72.

4) Fujiki, N. 1981. Using family linkages to reconstruct an isolated Japanese village's history. World Conference on Records. Series 826. 1-32.

5) Kanazawa, H. 1971. Studies on population genetics in the isolates. (V) Mukugawa, with special reference to the serum protein polymorphisms. $J_{p n} . J$. Const. Med. (in Japanese) 35: $24-47$.

6) Matsunaga, E. 1975. Distribution of polymorphic traits in the Japanese and neighboring populations. In Anthropological and Genetic Studies on the Japanese (Watanabe, S., Kondo, S. and Matsunage, E, eds.) JIBP Synthesis. Human Adaptability. Univ. Tokyo Press 2: 73206.

7) Mourant, A.E., Kopec, A.C., and Domaniewska-Sobczak, K. 1976. The Distribution of the Human Blood Groups and other Polymorphisms. Oxford Univ. Press.

8) Nishigaki, I. 1978. Studies on population genetics in the isolates. (VIII) Tomiyama, with special reference to the enzyme activity of polymorphic red cell enzymes. Jpn. J. Const. Med. (in Japanese) 42: 53-89. 
9) Nishigaki, I., Itoh, T., Fujiki, N., and Kondo, M. 1978. Phosphoglucomutase polymorphisms in an isolated community in Japan. $J p n . J$. Human Genet. 23: 377-382.

10) Nishigaki, I., Itoh, T., Suzuki, H., and Fujiki, N. 1980. Genetic studies of red cell glutamicpyruvic transaminase in some Japanese populations. Human Hered. 30: 33-38.

11) Wada, T. 1978. Studies on population genetics in the isolates. (VII) Okishima, with special reference to the relationship between polymorphic traits and morbidity. Jpn. J. Const. Med. (in Japanese) 42: 27-52.

12) Yamamoto, M., Saito, R., Watanabe, T., Kanazawa, H., Kondo, M., Hosokawa, K., and Fujiki, N. 1972. Genetic polymorphisms in four isolated communities in Kinki district. $J p n . J$. Human Genet. 17: 273-285.

13) Yamamoto, M., Nakanishi, K., Nakanishi, Y., Wada, T., Kanazawa, H., Nakai, T., Kondo, M., Hosokawa, K., Masuda, M., and Fujiki, N. 1974a. Inbreeding coefficients in Arihara. village, from pedigree study, phenotype and mating frequencies and correlation method. Jpn. J. Human Genet. 19: 217-227.

14) Yamamoto, M., Nakanishi, K., Nakanishi, Y., Wada, T., Kanazawa, H., Nakai, T., Kondo, M., Hosokawa, K., Masuda, M., and Fujiki, N. 1974b. The estimation of the effective population sizes from the random genetic drift and from the inbreeding coefficients. Jpn. J. Human Genet. 19: 229-234. 